\title{
Effect of human adipose-derived regenerative cells on temporomandibular joint healing in immunodeficient rabbits
}

\author{
Barbora Putnová ${ }^{1}$, Pavel Hurník ${ }^{2,3}$, Vladimír Jekl ${ }^{4,5}$, Dušan Žiak², Vladimír Machoň ${ }^{6}$, \\ Miša Škoričำ, Jiří Stránský7, Jan Štembírek ${ }^{7}$ \\ ${ }^{1}$ University of Veterinary and Pharmaceutical Sciences Brno, Faculty of Veterinary Medicine, \\ Department of Pathological Morphology and Parasitology, Brno, Czech Republic \\ ${ }^{2}$ University Hospital Ostrava, Department of Pathology, Ostrava, Czech Republic \\ ${ }^{3}$ University of Ostrava, Faculty of Medicine, Institute of Pathology, Ostrava, Czech Republic \\ ${ }^{4}$ University of Veterinary and Pharmaceutical Sciences Brno, Faculty of Veterinary Medicine, \\ Avian and Exotic Animal Clinic, Brno, Czech Republic \\ ${ }^{5}$ Veterinary Clinic Jekl \& Hauptman, Brno, Czech Republic \\ ${ }^{6}$ General Hospital Prague, Department of Oral and Maxillofacial Surgery, Prague, Czech Republic \\ ${ }^{7}$ University Hospital Ostrava, Department of Oral and Maxillofacial Surgery, Ostrava, Czech Republic
}

Received August 15, 2018

Accepted February 12, 2019

\begin{abstract}
Increasing research attention has focused on the use of stem cells (SCs) in regenerative and reparative medicine. Adipose-derived regenerative cells (ADRCs) are a relatively cheap and ethical source of SCs. Temporomandibular disorders (TMDs) have been reported with rising incidence over recent decades. The main aims of this study were to evaluate the effects of ADRCs application on the healing of both soft and hard temporomandibular joint (TMJ) tissues, and to assess the possible utilization of ADRCs in TMD treatment. We investigated the effects of human ADRCs on the healing of TMJ defects in immunodeficient rabbits. With no prior cultivation, ADRCs were applied to a surgically created defect in the cartilage of a rabbit TMJ. The healing process and inflammatory response were examined. Our results indicated that ADRCs supported repair processes in soft tissues. However, ADRC treatment induced a significant immune response in both soft and hard tissues, with hard tissues showing a higher level of bone remodelling. Non-differentiated ADRCs can be a promising tool for regenerative medicine of TMJ; however, deeper understanding of their effect on the cellular level is needed.
\end{abstract}

Joint regeneration, allotransplantation, animal model

The temporomandibular joint (TMJ) is a paired joint that connects the lower jaw to the temporal bone in mammals. A joint capsule attaches cranially to the temporal bone and caudally to the mandibular condyle neck, enclosing the entire articular system, including the condyle, articular disc, and fossa. This capsule is responsible for proprioception, articular structure nourishment, and prevention of joint dislocation (Berkovitz et al. 2009) The articular disc is located inside the TMJ, and divides it into two compartments that can be considered two individual joints: the meniscotemporal (suprameniscal) joint that enables translational movement, and the condylomeniscal (inframeniscal) joint that permits rotational movements. The articular surfaces comprise a hyaline/fibrocartilage composite with limited regenerative capacity. This joint structure is able to withstand the pressures occurring during mastication (Puricelli et al. 2012).

Regenerative cell therapy is currently the focus of extensive research, mostly involving the use of stem cells of various origins. Embryogenic stem cells are impractical for ethical reasons, therefore, attention is shifting to the use of adult stem cells or so-called tissue-specific stem cells, such as adipose-derived stem cells (ADSCs). The ADSCs can differentiate into other cell types, including endothelial cells and other cells that participate in angiogenesis

Address for correspondence:

MUDr. Jan Štembírek, Ph.D.

University Hospital Ostrava

17. listopadu 1790

708 52, Ostrava, Czech Republic 
(Planat-Benard et al. 2004), as well as pancreatic endocrine cells that produce insulin, glucagon, and somatostatin (Timper et al. 2006). An in vitro study of rheumatoid arthritis reported that ADSCs exhibited immunomodulative effects, reducing the production of some proinflammatory cytokines and increasing production of the anti-inflammatory cytokine IL-10 and of antigen-specific regulatory T-lymphocytes (Gonzalez-Rey et al. 2010). However, the specific mechanisms underlying these processes remain unclear. The ADSCs can also accelerate neovascularisation. An investigation of skin healing in diabetic mice revealed that the ADSCs can increase expression of the vascular endothelial growth factor (VEGF) and the hypoxia-inducible factor 1-alpha (HIF-1 $\alpha$ ) (Miranville et al. 2004; Gao et al. 2011). Another promising therapeutic use of ADSCs is in the treatment of ischaemiacaused pathologies (Moon et al. 2006). Experiments using bioactive glass or $\beta$-tricalcium phosphate scaffolds seeded with autologous ADSCs have been conducted to examine the role of ADSCs in healing jaw and skull injuries. The authors reported successful integration of the construct with the surrounding skeleton in 10 of 13 cases (Sandor et al. 2014).

While the stem cells' immunomodulative character and influence on tissue healing can be beneficial in reconstructive surgery and healing of problematic wounds, there is also a cancerogenic potential. It was shown that ADSCs co-cultivated with cancer cells can increase their multiplying ( $\mathrm{Yu}$ et al. 2008). Notably, in breast cancer, both local and intravenous administration of ADSCs reportedly induces tumour cell proliferation and increases the risk of metastases (Muehlberg et al. 2009). Studies have also described the use of undifferentiated xenogenous ADSCs in the rabbit, for treatment of neural tissue (Lasso et al. 2015) or osteochondral defects (Jang et al. 2014).

In this study, we used a relatively cheap and ethically sourced heterogeneous population of cells from adipose tissue, termed human adipose-derived regenerative cells (ADRCs). These cells include ADSCs, endothelial cells, smooth muscle cells, haematopoietic cells, and other stromal cells. Compared to pure ADSCs, ADRCs are easier and less expensive to obtain, and are already used in clinical practise at our hospital. We used a rabbit model because this animal is easy to breed and is bigger than mice or rats, and thus more suitable for some types of studies, including investigations of the TMJ. The present study was designed to examine the suitability of direct application of unfiltered ADRCs in a rabbit model for TMJ research, as well as the effects of such xenogenous cells on the healing of TMJ defects.

\section{Materials and Methods}

\section{Animals and immunosuppression}

Seventeen 10-month-old male outbred New Zealand White SPF rabbits (strain Crl:KBL) were obtained from Charles River Laboratories, Inc. (Wilmington, USA). These rabbits were individually housed in wiremesh cages at an animal care facility with controlled environmental conditions at the University of Veterinary and Pharmaceutical Sciences Brno, Czech Republic. The room temperature was maintained at $20-23{ }^{\circ} \mathrm{C}$, with 40-55\% relative humidity, and a 12-h light/dark cycle. The rabbits had free access to water, and were fed a complete pelleted diet and hay ad libitum. This study was performed in accordance with the ethical principles stated in the Declaration of Helsinki and approved by the Ethics Committee of the Faculty of Veterinary Medicine, University of Veterinary and Pharmaceutical Sciences Brno, approval No. 30307/2013-11. The animal housing, handling, and euthanasia were approved by the Branch Commission for Animal Welfare of the Ministry of Agriculture of the Czech Republic (project PP52-2013 UVPS).

After a three-week acclimatization period, the 17 rabbits were randomly divided into two groups: 9 in the experimental group and 8 in the control group. Prior to surgery, immunosuppression was induced in all rabbits via intramuscular administration of $2 \mathrm{mg} / \mathrm{kg}$ dexamethasone sodium phosphate (Dexamed, Medochemie Ltd, Limassol, Cyprus) three times at 6-h intervals (Jeklova et al. 2008). After surgery, all rabbits were administered $2 \mathrm{mg} / \mathrm{kg}$ of dexamethasone sodium phosphate 15 times at 2-day intervals (Jeklova et al. 2008).

Isolation of ADRCs

Adipose tissue was obtained from a single patient undergoing elective lipoplasty at the University Hospital Ostrava, with this patient's informed consent. The ADRCs were isolated from the adipose tissue using the Celution 800/CRS system (Cytori Therapeutics, Inc., San Diego, CA, USA). In this closed system process, 
the adipose tissue was digested with Celase ${ }^{\mathrm{TM}}$ Reagent (Cytori Therapeutics, Inc., San Diego, CA, USA). Figure 1 shows the cell type proportions according to the manufacturer. The collection of adipose tissue from human volunteers was approved by the Ethics Committee of FN Ostrava (Approval No. 654/2014).

\section{Experimental surgery}

The animals were placed under total anaesthesia, and open surgery was performed. The incision was made in the parotidomasseteric region, approximately $3 \mathrm{~cm}$ cranioventrally from the auricle base. Using a rotational tool with a spherical head, we created two defects in the condyle. Into these defects, we added 1 ml human ADRCs in the experimental group, and $1 \mathrm{ml}$ saline in the control group. Prior to the final suture, the wound was flushed with $0.5 \mathrm{ml}$ human ADRC solution in the experimental group, and $0.5 \mathrm{ml}$ saline in the control group (Plate III, Fig. 2).

\section{Histological assessment}

The animals were euthanized at two time points: 11 days (four from the experimental group, four from the control group) or 28 days (five from the experimental group, four the from control group) after the surgery. Joints were harvested together with the surrounding soft tissues. Samples were fixed in $10 \%$ buffered formaldehyde for 3 days, and then decalcified in EDTA solution with 4\% formaldehyde for approximately one year. We prepared $5 \mu \mathrm{m}$ thick paraffin sections, and then soft tissues were stained with haematoxylin and eosin, and hard tissues were stained with haematoxylin and eosin and Alcian blue. These histological sections were evaluated by two pathologists, with a focus on inflammatory and healing processes (Table 1). The validity of our results was verified using the STATISTICA software (StatSoft s.r.o., Pilsen, Czech Republic).

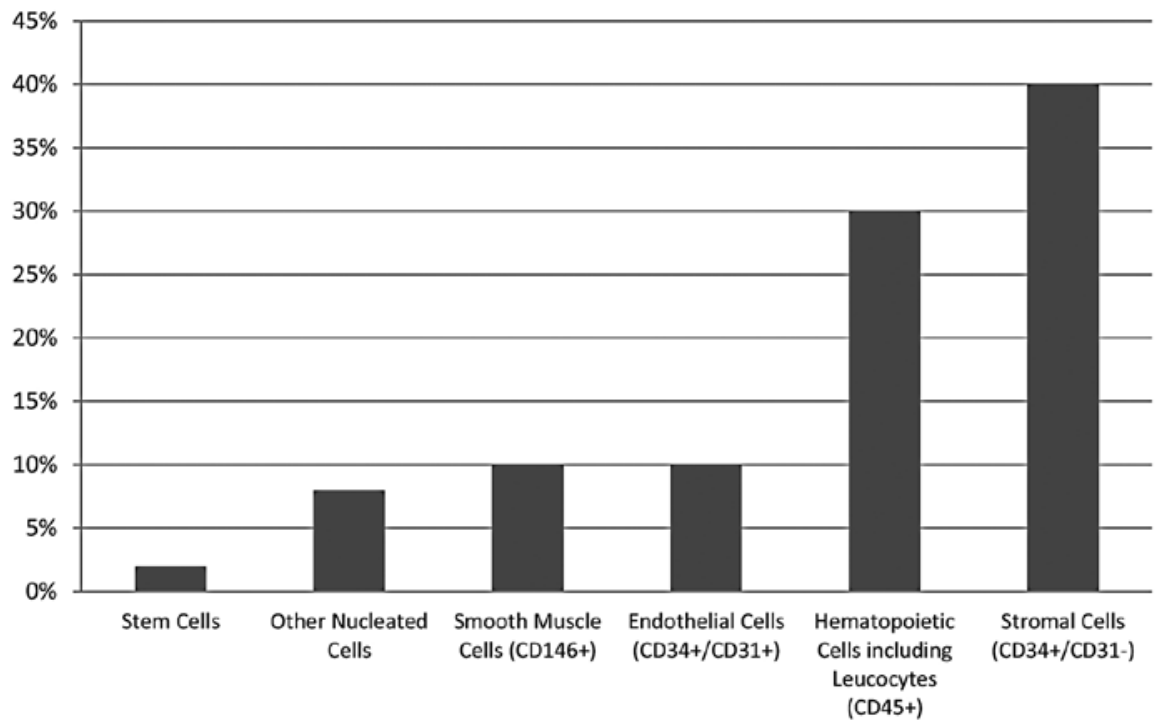

Fig. 1. Cell type proportions in the adipose-derived regenerative cells (ADRCs) isolated using the Celution 800/ CRS system, according to the manufacturer (Cytori Therapeutics).

\section{Results}

\section{Soft tissue healing after ADRC application}

At 11 days after surgery, both the experimental and control groups showed notable inflammatory reactions in the soft tissues. Compared to the control group, the ADRCtreated group showed less pronounced inflammatory infiltrate around the area of suture. The ADRC-treated animals also showed higher occurrence of Langhans giant cells and eosinophilic granulocytes in the inflammatory infiltrate, and a higher degree of necrotic changes in the soft tissues. Moreover, compared to samples from the control group, samples from ADRC-treated animals showed lower proliferation of newly formed fibrovascular tissue. 
Table 1. Tissue section features identified by microscopic evaluation.

\begin{tabular}{lc}
\hline Feature & Occurrence \\
\hline Inflammatory infiltrate & + \\
\hline Inflammatory infiltrate deep in the tissue & + \\
\hline Langhans giant cells in the sutura & - \\
\hline Langhans giant cells deep in the tissue & - \\
\hline Fibrovascular tissue & + \\
\hline Necrosis & - \\
\hline Blood vessel proliferation in the site of sutura & + \\
\hline Eosinophil granulocytes & + \\
\hline
\end{tabular}

+ present; - not present. of cartilage and bone, which was microscopically confirmed (Plate III, Fig. 3). The experimental group showed a higher amount of osteoclasts than the control group (Fig. 4). Compared to the control group, the ADRC-treated group showed a thicker layer of fibrosis underlying the defect, a lower frequency of fibrovascular tissue.

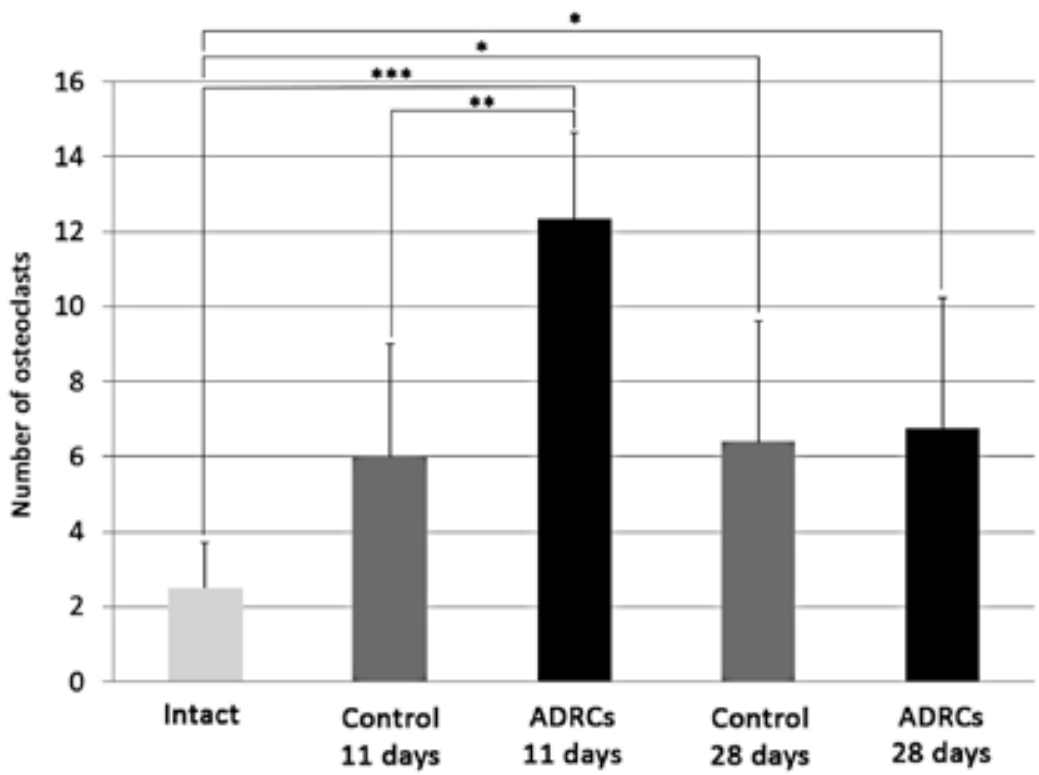

Fig. 4. Numbers of osteoclasts in the temporomandibular joint (TMJ) condyle during healing. Intact $=$ normal rabbit TMJ condyle. ADRC - adipose-derived regenerative cell. Y axis shows the osteoclastto-100 osteoblasts ratio (absolute value). Significance: $* P \leq 0.05 ; * * P \leq 0.01 ; * * * P \leq 0.001$ 
At 28 days after surgery, the ADRC-treated animals showed a more pronounced inflammatory reaction in the hard tissues compared to the control group. Surprisingly, the control group exhibited more newly formed cartilage than the experimental group. The two groups did not significantly differ regarding the layer of the fibrosis underlying the defect, or the amount of osteoclasts (Fig. 4). Similarly, the groups did not significantly differ in the other investigated indicators, such as the distance of the osteoblast activity from the experimental defect.

\section{Discussion}

Among the widely used laboratory animals, the pig is the only omnivore having a TMJ condyle similar in size to humans, along with a similar dentition type and means of joint loading during mastication (Stembirek et al. 2012). However, the use of a pig model has several drawbacks, including the high cost, the time required for histological assessment of hard tissues, and the more complicated immunological preparation of animals for transplantation of heterologous biologic material. Rats and mice were not suitable for the present research due to the small size of their TMJ, and its morphological differences from the human TMJ. Carnivores, such as dogs and cats, were not considered due to ethical reasons. These factors led us to use rabbits as our animal model. The rabbit TMJ shares several important similarities with the human TMJ, and is larger than the rat or mouse TMJ. Moreover, the rabbit TMJ model has been successfully used in other studies (Ali and Sharawy 1996; Ahtiainen et al. 2013; Embree et al. 2016).

The morphological complexity of the TMJ limits the options for surgical resolution of serious TMJ dysfunctions and injuries. Any surgical intervention in this area is burdensome for the patient. Joint transplants often have a restricted service life, and full joint function is not always maintained. Cell therapy is considered a promising tool in regenerative medicine (Madeira et al. 2015; Mardones et al. 2015). Joint prostheses and scaffolds with stem cells are under development, which may facilitate the integration of implanted bone or other tissues, decrease GvHD (graft-versus-host disease), and improve healing (Murphy et al. 2013).

A previous study describes the use of ADSCs in a therapeutic method for treating inflammatory and degenerative TMJ disorders (Detamore and Athanasiou 2003). Adipose-derived stem cells are typically recruited to injury sites, where they assist in injured tissue repair and regeneration, and locally differentiate into smooth muscle or endothelial cells that can participate in angiogenesis and neovascularisation (Lin et al. 2010). Adipose-derived stem cells can also differentiate into other tissue-specific cells, such as adipocytes in adipose tissue or chondrocytes in cartilage. Since they exhibit good chondrogenic potential in vitro and can assist in cartilage repair, they are theoretically better candidates for treatment of degenerative or inflammatory disorders than current medications (Shen et al. 2015; Wu et al. 2015). Direct application of ADRCs is the preferred method of use, since it minimizes the surgical interference with the integrity of the damaged joint; an outpatient procedure, such as arthrocentesis or arthroscopy, would be sufficient. The ADRCs could potentially help with regeneration and repair processes, reduce inflammatory reactions, and directly integrate into the damaged tissue, contributing to its reconstruction.

In this study, we used ADRCs, which are heterogeneous cell population that includes stem cells. One previous study tested a suspension of non-differentiated SCs for TMJ regeneration in rabbits with osteoarthritis (Chen et al. 2013). The animals in one group were treated with autologous non-differentiated bone marrow stromal stem cells (BMSCs), while the second group was treated with chondrogenic differentiated BMSCs. The study results show that the non-differentiated SCs had a significantly smaller effect on joint 
healing compared to the differentiated cells. Mapping of the BMSCs' fate revealed their survival in cartilage, subchondral bone, and synovial membrane for at least four weeks. The authors suggest that a suspension of autologous BMSCs can improve TMJ regeneration and slow the process of cartilage destruction in an osteoarthritic joint (Chen et al. 2013).

To our knowledge, no prior studies have investigated the application of human ADRCs in immunodeficient rabbits, or have described the effects of undifferentiated ADSCs in the TMJ region. Some authors consider successful differentiation to be a crucial step (Chen et al. 2013). In studies showing good results following the application of undifferentiated mesenchymal stem cells in joint osteoarthritis, the applied suspension has usually contained stem cells along with other factors that may have affected the results, such as plateletrich plasma (Koh and Choi 2012). Prior reports also describe the use of undifferentiated xenogenous ADSCs in rabbits for treating neural tissue (Las so et al. 2015) or osteochondral defects (Jang et al. 2014). These authors claim that even undifferentiated SCs can reduce the immune response and support better healing of defects. On the other hand, application of undifferentiated ADSCs during cornea xenotransplantation in rabbits did not influence the immune response or result in better graft integration. However, this treatment did increase inflammatory markers and neovascularisation (Fuentes-Julian et al. 2015). Most current data suggest that SCs can increase the proliferation of newly formed tissues. Accordingly, we found that prechondral fibrosis was more frequent in the experimental group, which may reflect an increased rate of repair processes in the treated joints (Murphy et al. 2013)

We considered the difference in osteoblast-to-osteoclast ratio to be a valid indication of bone remodelling and inflammatory response. This information can be easily obtained by light microscopy examination (Tanaka et al. 2005). We assumed that an increased number of osteoclasts signified a higher rate of bone remodelling. According to this assumption, the ADRC-treated animals showed a higher bone remodelling rate at 11 days after surgery compared to the control animals.

Prior studies have also suggested that SCs have benefits due to their immunomodulatory character (Bartholomew et al. 2002; Le Blanc et al. 2003; Tse et al. 2003; GonzalezRey et al. 2010; Murphy et al. 2013). However, our present results indicated that ADRCs had the opposite effect, as evidenced by the more pronounced inflammatory reaction in ADRC-treated joints. It is possible that this effect may have stemmed from the use of heterologous cells.

Adipose-derived regenerative cells contain endothelial cells and ADSCs, and can reportedly induce neovascularisation due to increased VEGF expression in the treated tissue (Miranville et al. 2004; Zhu et al. 2010; Gao et al. 2011; Matsugami et al. 2014). Our results confirmed this expectation, with a higher number of vessels observed in soft tissues in the experimental group compared to the control group.

To prevent GvHD, we used an immunosuppressive protocol tested for rabbits (Jeklova et al. 2008). Despite this measure, we observed a higher than expected immunologic response to the heterologous cells in the experimental group. Our results did not confirm the previously described immunomodulative effects of ADRCs and ADSCs (Bartholomew et al. 2002; Le Blanc et al. 2003; Tse et al. 2003; Zhu et al. 2010). However, our present data do not enable us to determine whether this was due to the stem cells themselves or to the heterologous character of the ADRCs.

In conclusion, this study was designed to evaluate the potential of unprocessed ADRCs for TMD treatment. Adipose-derived regenerative cells have the advantages of being simple to use, requiring reduced time, providing increased comfort for the potential patient, and lowering the procedure costs. Our present results indicated that ADRC treatment promoted a slight increase of newly formed vessels in soft tissues, which can be considered a marker of improved reparative processes. Application of the ADRC suspension resulted in a stronger inflammatory reaction and a more pronounced foreign body reaction compared 
to the control group. These observations can be explained by the fact that the applied ADRCs were heterogeneous, such that an immune-mediated reaction occurred despite immune suppressive therapy. Compared to controls, the ADRC-treated animals also showed a higher rate of bone remodelling. Overall, we conclude that ADRCs may be a promising tool for TMD treatment. Further studies are needed to better understand their effects on tissues in vitro.

\section{Conflict of Interest}

We have no conflicts of interest to disclose.

\section{Acknowledgements}

This work was supported by the Ministry of Health of the Czech Republic, RVO-FNOs/2013.

\section{References}

Ahtiainen K, Mauno J, Ella V, Hagstrom J, Lindqvist C, Miettinen S, et al. 2013: Autologous adipose stem cells and polylactide discs in the replacement of the rabbit temporomandibular joint disc. J R Soc Interface 10: 20130287

Ali AM, Sharawy MM 1996: An immunohistochemical study of collagen types III, VI and IX in rabbit craniomandibular joint tissues following surgical induction of anterior disk displacement. J Oral Pathol Med 25: $78-85$

Bartholomew A, Sturgeon C, Siatskas M, Ferrer K, McIntosh K, Patil S, et al. 2002: Mesenchymal stem cells suppress lymphocyte proliferation in vitro and prolong skin graft survival in vivo. Exp Hematol 30: 42-48

Berkovitz BK, Holland GR, Moxham BJ, Holland GR, Moxham BJ 2009: Oral Anatomy, Histology and Embryology. Mosby; $4^{\text {th }}$ International edition, vol. 4

Chen K, Man C, Zhang B, Hu J, Zhu SS 2013: Effect of in vitro chondrogenic differentiation of autologous mesenchymal stem cells on cartilage and subchondral cancellous bone repair in osteoarthritis of temporomandibular joint. Int J Oral Maxillofac Surg 42: 240-248

Detamore MS, Athanasiou KA 2003: Structure and function of the temporomandibular joint disc: implications for tissue engineering. J Oral Maxillofac Surg 61: 494-506

Embree MC, Chen M, Pylawka S, Kong D, Iwaoka GM, Kalajzic I, Yao H, Sun D, Sheu TJ, Koslovsky DA, Koch A, Mao JJ 2016: Exploiting endogenous fibrocartilage stem cells to regenerate cartilage and repair joint injury. Nat Commun 7: 13073

Fuentes-Julian S, Arnalich-Montiel F, Jaumandreu L, Leal M, Casado A, Garcia-Tunon I, Hernandez-Jimenez E, Lopez-Collazo E, De Miguel MP 2015: Adipose-derived mesenchymal stem cell administration does not improve corneal graft survival outcome. PloS one 10: e0117945

Gao W, Qiao X, Ma S, Cui L 2011: Adipose-derived stem cells accelerate neovascularization in ischaemic diabetic skin flap via expression of hypoxia-inducible factor-1alpha. J Cell Mol Med 15: 2575-2585

Gonzalez-Rey E, Gonzalez MA, Varela N, O’Valle F, Hernandez-Cortes P, Rico L, Büscher D, Delgado M 2010: Human adipose-derived mesenchymal stem cells reduce inflammatory and $\mathrm{T}$ cell responses and induce regulatory T cells in vitro in rheumatoid arthritis. Ann Rheum Dis 69: 241-248

Jang KM, Lee JH, Park CM, Song HR, Wang JH 2014: Xenotransplantation of human mesenchymal stem cells for repair of osteochondral defects in rabbits using osteochondral biphasic composite constructs. Knee Surg Sports Traumatol Arthrosc 22: 1434-1444

Jeklova E, Leva L, Jaglic Z, Faldyna M 2008: Dexamethasone-induced immunosuppression: a rabbit model. Vet Immunol Immunopathol 122: 231-240

Koh YG, Choi YJ 2012: Infrapatellar fat pad-derived mesenchymal stem cell therapy for knee osteoarthritis. Knee 19: $902-907$

Lasso JM, Perez Cano R, Castro Y, Arenas L, Garcia J, Fernandez-Santos ME 2015: Xenotransplantation of human adipose-derived stem cells in the regeneration of a rabbit peripheral nerve. J Plast Reconstr Aesthet Surg 68: e189-197

Le Blanc K, Tammik L, Sundberg B, Haynesworth SE, Ringden O 2003: Mesenchymal stem cells inhibit and stimulate mixed lymphocyte cultures and mitogenic responses independently of the major histocompatibility complex. Scand J Immunol 57: 11-20

Lin CS, Xin ZC, Deng CH, Ning H, Lin G, Lue TF 2010: Defining adipose tissue-derived stem cells in tissue and in culture. Histol Histopathol 25: 807-815

Madeira C, Santhagunam A, Salgueiro JB, Cabral JM 2015: Advanced cell therapies for articular cartilage regeneration. Trends Biotechnol 33: 35-42 
Mardones R, Jofre CM, Minguell JJ 2015: Cell therapy and tissue engineering approaches for cartilage repair and/ or regeneration. Int J Stem Cells 8: 48-53

Matsugami H, Harada Y, Kurata Y, Yamamoto Y, Otsuki Y, Yaura H, Inoue Y, Morikawa K, Yoshida A, Shirayoshi Y, Suyama Y, Nakayama B, Iwaguro H, Yamamoto K, Hisatome I 2014: VEGF secretion by adipose tissuederived regenerative cells is impaired under hyperglycemic conditions via glucose transporter activation and ROS increase. Biomed Res Int 35: 397-405

Miranville A, Heeschen C, Sengenes C, Curat CA, Busse R, Bouloumie A 2004: Improvement of postnatal neovascularization by human adipose tissue-derived stem cells. Circulation 110: 349-355

Moon MH, Kim SY, Kim YJ, Kim SJ, Lee JB, Bae YC, Sung SM, Jung JS 2006: Human adipose tissue-derived mesenchymal stem cells improve postnatal neovascularization in a mouse model of hindlimb ischemia. Cell Physiol Biochem 17: 279-290

Muehlberg FL, Song YH, Krohn A, Pinilla SP, Droll LH, Leng X, Seidensticker M, Ricke J, Altman AM, Devarajan E, Liu W, Arlinghaus RB, Alt EU 2009: Tissue-resident stem cells promote breast cancer growth and metastasis. Carcinogenesis 30: 589-597

Murphy MK, MacBarb RF, Wong ME, Athanasiou KA 2013: Temporomandibular disorders: a review of etiology, clinical management, and tissue engineering strategies. Int J Oral Maxillofac Implants 28: e393-414

Planat-Benard V, Silvestre JS, Cousin B, Andre M, Nibbelink M, Tamarat R, Clergue M, Manneville C, SaillanBarreau C, Duriez M, Tedgui A, Levy B, Pénicaud L, Casteilla L 2004: Plasticity of human adipose lineage cells toward endothelial cells: physiological and therapeutic perspectives. Circulation 109: 656-663

Puricelli E, Ponzoni D, Munaretto JC, Corsetti A, Leite MG 2012: Histomorphometric analysis of the temporal bone after change of direction of force vector of mandible: an experimental study in rabbits. J Appl Oral Sci 20: 526-530

Sandor GK, Numminen J, Wolff J, Thesleff T, Miettinen A, Tuovinen VJ, Mannerström B, Patrikoski M, Seppänen R, Miettinen S, Raitiaunen M, Öhman J 2014: Adipose stem cells used to reconstruct 13 cases with craniomaxillofacial hard-tissue defects. Stem Cells Transl Med 3: 530-540

Shen J, Gao Q, Zhang Y, He Y 2015: Autologous plateletrich plasma promotes proliferation and chondrogenic differentiation of adiposederived stem cells. Mol Med Rep 11: 1298-1303

Stembirek J, Kyllar M, Putnova I, Stehlik L, Buchtova M 2012: The pig as an experimental model for clinical craniofacial research. Lab Anim 46: 269-279

Tanaka Y, Nakayamada S, Okada Y 2005: Osteoblasts and osteoclasts in bone remodeling and inflammation. Curr Drug Targets Inflamm Allergy 4: 325-328

Timper K, Seboek D, Eberhardt M, Linscheid P, Christ-Crain M, Keller U, Müller B, Zulewski H 2006: Human adipose tissue-derived mesenchymal stem cells differentiate into insulin, somatostatin, and glucagon expressing cells. Biochem Biophys Res Commun 341: 1135-1140

Tse WT, Pendleton JD, Beyer WM, Egalka MC, Guinan EC 2003: Suppression of allogeneic T-cell proliferation by human marrow stromal cells: implications in transplantation. Transplantation 75: 389-397

Wu SC, Hsiao HF, Ho ML, Hung YL, Chang JK, Wang GJ, Wang CZ 2015: Suppression of discoidin domain receptor 1 expression enhances the chondrogenesis of adipose-derived stem cells. Am J Physiol Cell Physiol 308: C685-696

Yu JM, Jun ES, Bae YC, Jung JS 2008: Mesenchymal stem cells derived from human adipose tissues favor tumor cell growth in vivo. Stem Cells Dev 17: 463-473

Zhu M, Zhou Z, Chen Y, Schreiber R, Ransom JT, Fraser JK, Hedrick MH, Pinkernell K, Kuo HC 2010: Supplementation of fat grafts with adipose-derived regenerative cells improves long-term graft retention. Ann Plast Surg 64: 222-228 
Plate III

Putnová B. et al.: Effect of human ... pp. 49-56
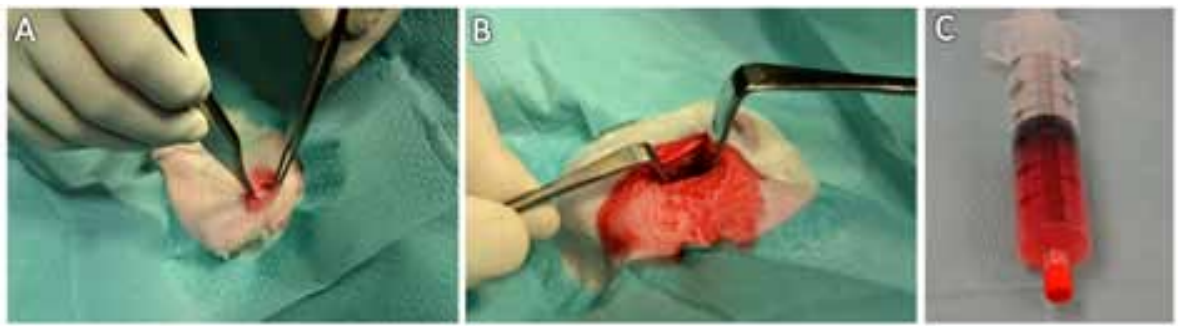

Fig. 2. Experimental surgery. (A) The incision was made in the parotidomasseteric region, approximately $3 \mathrm{~cm}$ cranioventrally from the auricle base (B) The temporomandibular joint (TMJ) was exposed. (C) The prepared adipose-derived regenerative cell suspension.
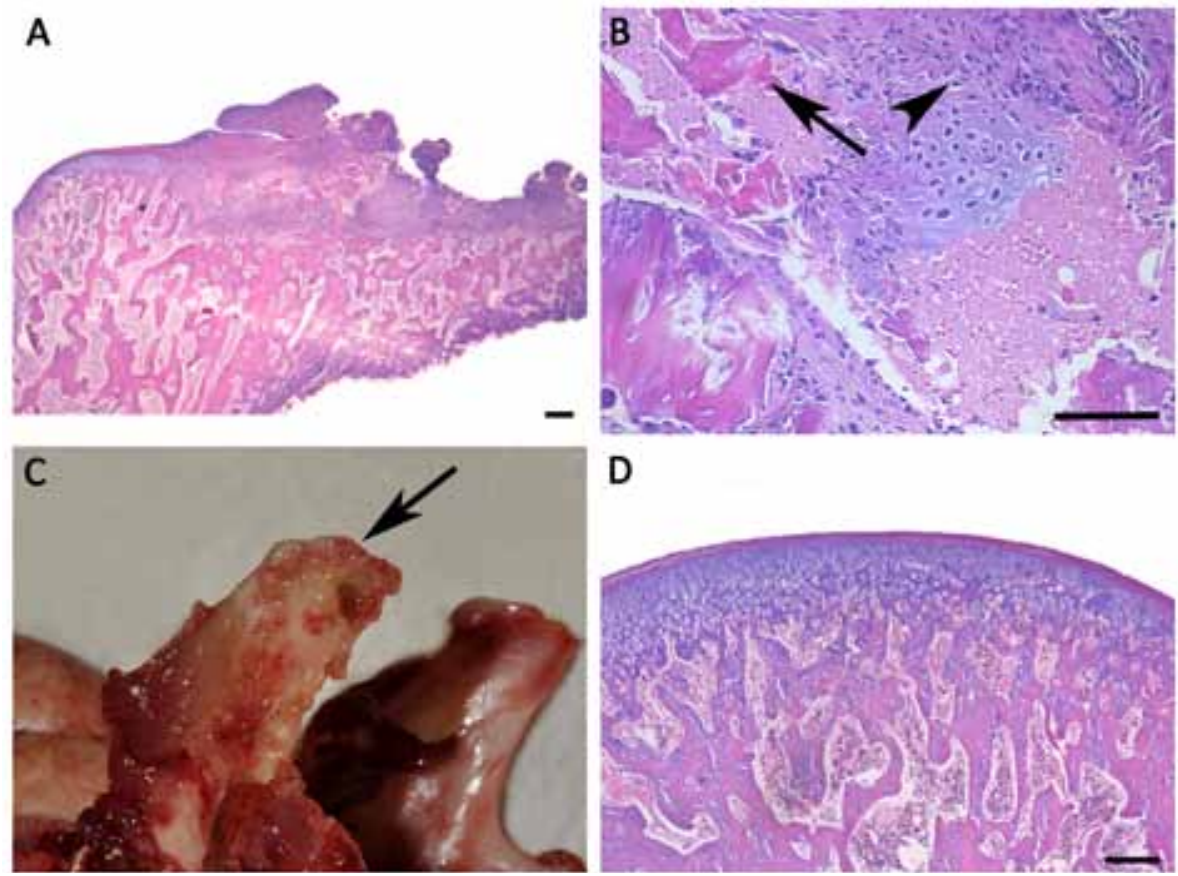

D

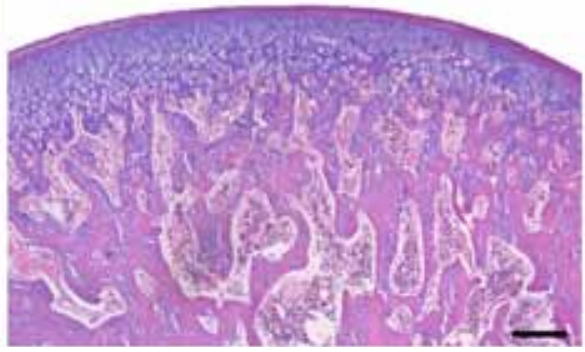

Fig. 3. Healing of hard tissues after adipose-derived regenerative cell (ADRC) application. (A) The loss of cartilage and bone resorption observed in one case. (B) Bone necrosis (arrow) and fibrosis formation (arrowhead). (C) Macroscopic appearance of the temporomandibular joint (TMJ) condyle shown in A. (D) Normal rabbit TMJ condyle surface presented for comparison. Scale bar, $100 \mu \mathrm{m}$. Sections are stained with Alcian blue and haematoxylin-eosin. 